\title{
ASP: THE FOURTH-PARTY COUNTERPARTS IN THE EVOLVING LOGISTICS INDUSTRY
}

\author{
Antonio G.N. Novaes, Monica M.L. Detoni \\ Federal University of Santa Catarina \\ Department of Industrial Engineering \\ Florianópolis, SC, BRAZIL \\ email:novaes@eps.ufsc.br
}

\begin{abstract}
The increasing use of IT in logistics operations is one of the factors behind the growing demand for third-party logistics services (3PL). In this context, new organizational schemes have appeared, such as the network structure, leading to greater flexibility and adaptability to external demand variations. In particular, many 3PL providers are sharing technology and services with clients in an ASP environment. The paper investigates the evolution and trends of 3PLs, in Brazil and abroad. Except large international organizations, the Brazilian 3PL providers lack financial resources to buy advanced applied software and IT. As a consequence, ASP have a good marketing opportunity in this context. We further discuss the emergence of combined ASPs and fourthparty logistics (4PL) suppliers.
\end{abstract}

\section{INTRODUCTION}

The increasing use of IT in logistics operations is regarded as one of the main factors behind the growing demand for third-party logistics services (Lewis and Talalayevsky, 2000; Sum and Teo, 1999). As a consequence, the logistics service industry is showing a constant growth. In this context, new inter-organizational arrangements have appeared, such as the network structure, leading to greater flexibility and adaptability to external demand variations. The information and communication technology is the engine that governs all this reconfiguration. In this setting, the third-party logistics providers (3PL) are sharing technology and services with their counterparts in an ASP environment.

The paper investigates the evolution and trends of $3 \mathrm{PL}$, as related to the increasing use of IT. In Brazil, excepting large international logistics organizations, 3PLs usually lack financial resources to buy advanced applied software and IT. As a consequence, ASP has a good market opportunity in this context. In order to support our analysis, two market surveys of 3PLs prepared by a Brazilian magazine (Revista Tecnologistica, 2001a) and Booz Allen \& Hamilton (Revista Tecnologistica, 2001b) are analyzed and commented. We further discuss the double role a few ASP/4PL (fourth-party logistics providers) in Brazil and abroad. 


\section{THIRD-PARTY LOGISTICS (3PL)}

The idea of outsourcing isolated logistics activities to external service providers is not new. Transportation and warehousing activities, for example, have been performed by third-party service providers for many years. However, this kind of conventional outsourcing has been based on simple considerations, with the client choosing the lowest price alternative that meets some pre-defined service requirements. In most cases these services have been performed by more than one third-party player in order to ensure a healthy competition. In this traditional scenario the involved parties have shown "arm's length" relationships with a minimum of information interchange (Laarhoven et al, 2000; Skjoett-Larsen, 2000).

In the last years, however, a noticeable change has been detected in the arrangements and relationships among shippers and logistics service providers. There is an increasing recognition of logistics as a source of potential competitive advantage by companies, with the resulting rapid growth of the logistics service industry. Initially, the primary driving forces in such a phenomenon were the reduction of costs and the release of capital to other investing ventures. Presently, the driving forces of business have a clearer strategic nature. The objective now is to increase market share, improve the service level and increase flexibility in order to satisfy customers' needs. As a result, the parties are building long-term alliances, which are often combined with changes in both organization and information systems (Skjoett-Larsen, 2000). The employment of external parties, with this broader cooperative arrangement, to perform formerly in-house logistics activities, is called Third-Party Logistics (3PL) in the literature.

3PL can be defined as activities carried out by a logistics service provider on behalf of a shipper and consisting of at least some management function and the execution of transportation and/or warehousing tasks (Laarhoven et al, 2000). The presence of management activities differentiates the 3PLs from the traditional "arm's length" relationship between parties. Of course, actual 3PL settings may include other additional activities, such as inventory management, information related activities such as tracking and tracing, assembly of products, and supply chain management, among others.

Some of the 3PL providers are asset-based companies, offering services well beyond simple brokerage. Non-asset based 3PLs, such as freight forwarders, act as intermediaries to contract for transportation, warehouse and related services. Most of the large 3PLs, on the other hand, offer services of both kinds. The integration between the client firm and the companies that provide logistics services varies as a function of the complexity and customization required.

In principle, businesses are normally reluctant to abdicate responsibility for products and services that are regarded as providing marketplace differentiation or a source of competitive advantage. Normally there is a greater likelihood for conflicting competition in the transactional side of business than in the logistics functions. This is because activities involved in the latter are less related to transaction-creating efforts such as advertising, pricing, credit, image, etc (Gill and Allerheiligen, 1996). Moreover, there are unique opportunities for functional specialization and returns to scale in logistics activities. In practical terms, US 
spending on transportation of manufactured goods via land, sea, and air was US \$ 436 billion in 1998. In 1999, the figure had grown $15 \%$, to US\$ 500 billion. Of this total, about $80 \%$ was spent on trucking. And approximately half of the trucking amount (about US\$200 billion) was spent by manufacturing and commercial companies that managed their own fleets.

\section{APPLICATION SERVICE PROVIDERS (ASP)}

The New Economy is a networked economy: It is characterized by unprecedented levels of electronically-mediated communication and commerce. In this context, a new form of business has appeared recently: the Application Service Provider (ASP), in which client companies access application software on remote Internet servers (Eisenmann and Pothen, 2001). Application software is thus "rented", i.e., customers make subscription payments to the ASPs, rather than buying and installing software in their own computers (Applegate and Collura, 2001).

From a timid start, with companies outsourcing basically IT services, the situation evolved to a point in which even strategic applications are being transferred to thirdparty system providers. One key point in this outsourcing process is application hosting. At the beginning, Internet Service Providers (ISPs) offered access services (i.e., access to Websites and to message exchange), also hosting other services as, for instance, the management of Websites. These services evolved naturally to other configurations, in special the one in which a new class of application software vendors started to use the hosting environment to provide Internet-based applications. A third stage has been characterized by the emergence of "portals" (e.g., Yahoo, Lycos). Some ASPs, taking advantage of the longer stretch of time that users lingered at the portal, began aggregating complementary suites of applications, accessible through a single Website (Eisenmann and Pothen, 2001).

ASP helps to reduce "commerce friction". First, it reduces the frequently high down-payments required to acquire packaged software licenses. Second, it bypasses the need for recruiting or retraining IT personnel to install and maintain in-house software. And third, it eliminates the need to build and maintain the IT infrastructure necessary to support the applications. Logistics and logistics-related services are expected to represent about 59\% of the ASP market by 2003. On the other hand, almost $93 \%$ of the ASP customers will be formed by small and medium firms in the US market (Eisenmann and Pothen, 2001).

\section{EVOLVING FROM AN ASSET-BASED TO AN IT-BASED STRUCTURE: THE FedEx CASE}

FedEx was founded in 1973 to capitalize on the needs of businesses for speed and reliability of deliveries, leading to shortened lead-times. Its next-day delivery service was an important advancement in the distribution industry. Despite losses in the first three years of operation due to high capital investments in the physical infrastructure of the business, the company began to show profits from 1976 onwards. In 1994, it became the first big logistics operator to launch a Website which included tracking and tracing capabilities. By applying IT to the business, FedEx leapfrogged the rest of the industry. Today FedEx is a US\$ 20 billion company (www.fedex.com), 
spending about US\$ 1 billion annually on IT developments, plus millions more in capital expenditure, with an IT workforce in excess of 5,000 people $(\mathrm{Ng}, 2000)$.

As early as 1979, a centralized computer system (COSMOS) kept track of all packages handled by the company. The Internet permitted the refinement of the COSMOS system In 1999, FedEx adopted Netscape software as the primary technology for accessing its corporate intranet sites $(\mathrm{Ng}, 2000)$.

During the last decade the company reinforced its commitment to becoming more than just an express delivery company. By 1999, FedEx decided to offer solutions at all levels of the supply chain. Along the first twenty years of existence, FedEx services had been mostly of asset-based nature, with a large network of warehouses, aircrafts, and trucks. During the last decade, however, the focus of the company's strategy started to shift toward IT solutions.

\section{ASP IN LOGISTICS}

Fourth-party logistics (4PL), a new outsourcing concept, is defined as a supply chain integrator who assembles and manages the resources, capabilities, and technology of its organization with those of complementary service providers to deliver a comprehensive supply chain solution, combining the capabilities of management consulting, IT technology and 3PL-providers (Skjoett-Larsen, 2000). Figure 1 shows a schematic view of a typical present-day supply-chain architecture, with a 4PL provider giving support to shippers, carriers and even 3PLs (Chiu, 1996). The physical flow of products is quite similar to the traditional asset-based configuration. But IT infrastructure allows for quicker business expansion which, in its turn, leads to economies of scale. Some cases of successful ASP endeavors in the logistics industry are discussed next.

\subsection{CargoNet}

CargoNet Transportation Community Network Limited was established in 1994 with the aim of developing electronic commerce services tailored to the trade and transportation community in Hong Kong and Southern China (Damsgaard and Farhoomand, 1999). Its initial target was to launch an EDI service that would meet the needs of small and medium-sized enterprises, typical of the Hong Kong economy, as well as catering for the large companies involved in sea cargo.

Cargo Net's big opportunity was to function as a central clearing house for the European Community networks operating in Hong Kong. Inevitably, in most trading transactions, small and medium enterprises (SMEs) were involved in the process. Their lack of knowledge and skills to implement and operate a number of separate eCommerce systems was the most significant barrier to efficient electronic commerce within international trading and transportation. Some SMEs were connected to networks. However, instead of benefiting the SMEs, it was rather a burden for them because information entered to support one electronic transaction had to be re-typed to fit another electronic transaction. Using CargoNet's web-base would provide them with a common interface and access to all necessary parties to complete a business transaction. 


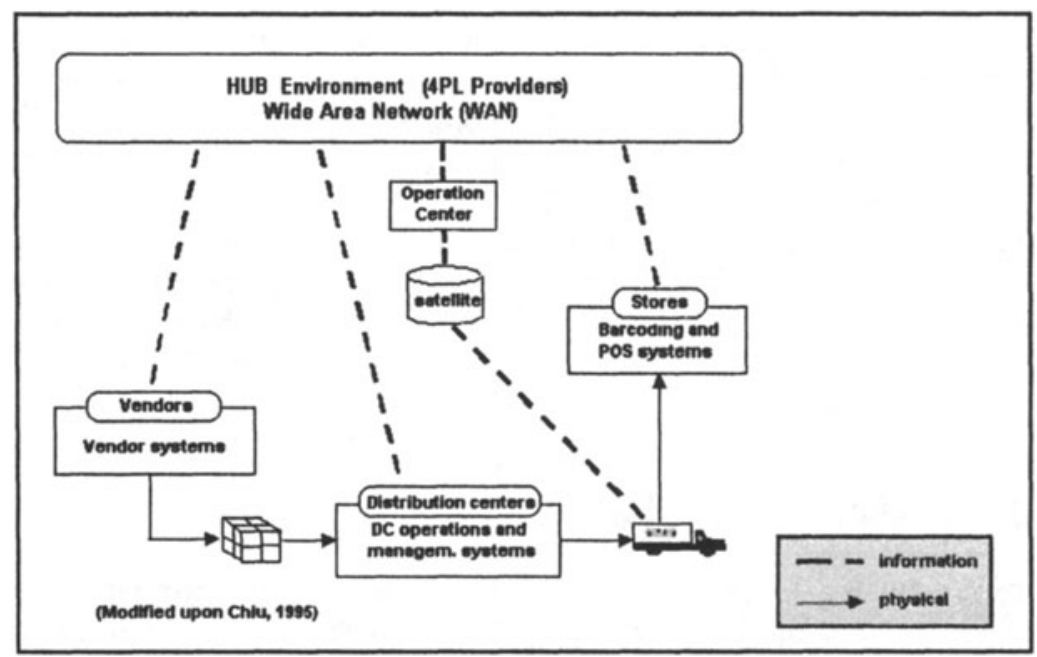

Figure 1 - A typical 4PL structure

\subsection{PLex.com}

The key players in the transportation of goods in the US fall into one or more of these three groups: shippers, carriers and 3PL providers. Shippers, include manufacturers and distributors from different industries (food, electronics, chemicals, consumer goods, etc), each of which with its own particular transportation requirements. Carriers often specialize in one particular type of transportation: highway, rail, sea, or air.

Shippers' traffic managers played a crucial role in deciding how a company's product load would be delivered. In the case the shipper did not maintain a proprietary fleet of vehicles, the manager began by contacting various carriers to find shipping costs and supply availability. The larger and more sophisticated shippers often relied on automated transportation management systems (TMS) to speed the process. If these contacts failed, the manager could contact a broker in order to learn about prospective carriers. The matching process was cumbersome and often the resulting compromise would not yield satisfactory cost savings due to time constraints and the inefficiency of the search process (Dror, 2000).

Carriers shared many of the shippers' matching and pricing problems. Because they often operated on tight profit margins, increasing asset utilization was a top priority. One of the main carrier's problems was to fill their trucks on the return leg of the trip. About 12 to $20 \%$ of the road miles were traveled without a payload, with an estimated annual loss of US\$22 billion in 1994. This loss raised to more than US\$ 38 billion by the end of 1999 (Dror, 2000).

Often, the large 3PLs had the resources to offer sophisticated e-commerce solutions to their customers. Unlike other supply chain service providers, which attracted shippers and carriers with the promise of the lowest cost for nondifferentiated services, 3PLs have access to critical information and knowledge of particular interest to shippers and carriers. Specifically, they added value to the 
supply chain by ascertaining and utilizing the method of transporting goods that best met the customer's needs. Logistics providers missed opportunities to increase their revenues when they could not make matches for all of their customers requests. They also missed opportunities to sell more high-margin value-added services because of the amount of time they spent on brokerage.

In the year 2000 three young entrepreneurs, two of them just graduated from the Harvard Business School, founded 3PLex.com, an ASP targeting mainly the 3PL industry in the US. Its mission is to help 3PLs and intermodal participants to compete more efficiently. One of 3Plex's systems is the Transportation Management Solutions (TMS) which enables client 3PLs to lower the shipping costs of their customers by generating optimal shipping plans that balance logistics strategies, customer service policies, transit time and other options. (www.3plex.com).

\section{3PL AND 4PL IN BRAZIL}

Since the opening of the Brazilian Economy about a decade ago, the industry and commerce in the country have shown positive development, both qualitative and quantitative. The country's productive sector has been served by traditional cargo carriers, basically trucking companies. Today, many of these transportation companies are striving to convert themselves into 3PLs. Large international 3LPs, such as Ryder, Penske, TNT, Danzas, and McLane have established branches in Brazil. But the 3PL market is still incipient in the country. In fact, the ten largest 3PLs operating in Brazil presented total gross revenues of about US\$ 733 million in 2000 . The leading company of the group reported gross revenues of US\$ 123 million in that same year (IMAM, 2001). Of course, these figures are far from the values obtained by the leading companies in the US and Europe. A good appraisal of e-commerce perspectives in Latin America can be found in Monteiro et al (2001).

\subsection{The first 3PL survey}

One important source of information on 3PLs in Brazil is Revista Tecnologistica, a well-known logistics magazine, which makes an annual survey of 3PL operators. The year 2001 questionnaire (Revista Tecnologistica, 2001a) was answered by 106 logistics operators acting in Brazil. The companies were asked to release information on matters regarding gross revenues, operating time in the market, number of clients, number of employees, assets (warehouse area per type, fleet of cargo vehicles), traditional warehousing and transportation services, logistics and logistics-related services, and technological features employed by the interviewed (hardware and software).

In the survey, $64 \%$ of the respondent companies reported to have both types of assets, warehouses and trucks, offering two types of services, conventional and logistics services. About $33 \%$ of the respondents, on the other hand, indicated proprietary assets, but only warehouses, with no proprietary trucks. Only two companies are service-oriented, with no truck and warehousing assets. And one respondent firm is responsible for traditional transportation and warehousing services, not offering services of logistics nature. It is worth observing that the Revista Tecnologistica's survey did not included IT integrated systems, which are 
today one key element in 3PL successful operations. In fact, a significant part of the executives of the trucking companies that are striving to become 3PLs in Brazil do not grasp the full meaning of this assertion, since their firms make only partial use of IT. In this context, ASP focussing on logistics integrated solutions have a promising market in Brazil and in other Latin-American countries. The prospective 3PLs have limited IT capabilities and limited capital to invest on such features.

\subsection{The second 3PL survey}

The survey was performed by Booz Allen \& Hamilton (Revista Tecnologistica, $2001 \mathrm{~b})$. A questionnaire was sent to 135 logistics operators acting in Brazil. The basic selection criterion was the offering of at least two logistics services. For instance, an operator offering transportation and warehousing services would be qualified to be interviewed. Sixty-seven firms (50\% of the sample) answered the questionnaire. The 3PLs were classified into two broad groups. The first one, comprising the majority of the respondents were operations oriented, offering transportation, warehousing and other physically-related services. The second group included the firms that offered integrated solutions covering the supply chain. The first group was further divided into Basic National Providers and Basic Regional Providers. The second group was formed by four sub-groups: Incipient National Integrators, Incipient Regional Integrators, Express Service Providers, and Client Oriented Integrators. The leading firms in the latter bracket were Penske, Mc Lane, Ryder and TNT.

The 3PL industry in Brazil is quite new, with an average age of $5 \frac{1}{2}$ years and heavily concentrated in the industrially developed South East . The firms are small when compared to its international counterparts, with few of them offering rail and maritime transportation options in addition to road transportation. Shippers in Brazil tend to qualify 3PLs based on service level, but select them based ultimately on price. The interviewed 3PLs pointed out the burdensome Brazilian taxation system and the infrastructure deficiencies (highways, ports, customs, etc.) as the main barriers to the development of that sector.

Both surveys show that 3PLs in Brazil are attempting to sell logistics solutions to supply chain clients. But this can only be achieved with adequate technology and expertise, which can be expedited by using ASP/4PL.

\subsection{Some 4PLs operating in Brazil}

Via Katalyx (www.viakatalyx.com) was created to develop and operate leading B2B e-commerce initiatives in Latin America, Spain and Portugal. Backed by the Telefonica Group, the leading telecommunications service provider in the Spanishand Portuguese-speaking world, and the Bilbao Vizcaya Argentaria Bank (BBVA), a leading financial institution in Latin America and Spain, Katalyx offers ASP solutions through strategic alliances with leading B2B e-commerce industry.

As advertised in the company's Web-site, Katalyx Transportation offers state-ofthe-art technology to shippers, carriers and 3PLs, creating a new, more efficient way of doing business. This platform will allow members the opportunity to eliminate outdated business practices and essentially leapfrog into the New Economy, without having to make substantial investment in technology.

Cia Vale do Rio Doce, a traditional mining and logistics enterprise of Brazil, has recently created two subsidiaries, Valepontocom and Multistrata, to act as 4PLs in 
the B2B commerce in Brazil. Multistrata acts in the Mercosul environment and has established a partnership with Manugistics, which is a leader on IT applications to Logistics.

A large Brazilian wholesaler, the Martins Group, has created through its subsidiary Marbo Logistica a new company, Intecom, in partnership with the JP Morgan Bank, focussing on the virtual commerce. The back-office Intecom system operates as an ASP, offering specialized logistics systems to its clients (www.intecom.com.br).

\section{CONCLUSIONS}

Except for some large well-known logistics providers that have already established their branches in Brazil, the great majority of prospective 3PLs acting in the country lack the up-to-date expertise and technology to offer more sophisticated and streamlined logistics services. In this context, a number of 4PL enterprises are starting operations in Brazil, integrating the various elements of the supply chain. They are in fact ASPs specializing on logistics services and their activities will facilitate and shorten the transition phase to the New Economy.

\section{REFERENCES}

1. Applegate, LM, Collura, M. Emerging e-business models: lessons from the field, Harvard Business School publication $\mathrm{n}^{\circ} 9-801-172$, July 2001.

2. Chiu, HN. The integrated logistics management system: a framework and case study, International Journal of Physical Distribution \& Logistics Management, 1996 ; 25: 4-22.

3. Damsgaard, J, Farhoomand, AF. Cargonet transportation community network limited, Centre for Asian Business Cases, School of Business, The University of Hong Kong, publication $n^{\circ}$ HKU013, Nov 1999.

4. Dror, J . 3Plex.com, Harvard Business School publication n 9-801-152, Oct 2000.

5. Eisenmann, T, Pothen, S. Application service providers, Harvard Business School publication n 9801-310, Jan 2001.

6. Gill, .LE , Allerheiligen, RP. Co-operation in channels of distribution: physical distribution leads the way, International Journal of Physical Distribution \& Logistics Management, 1996 ; 26: 49-63.

7. IMAM. The biggest ten logistics operators in Brazil (in Portuguese), LOG Movimentação \& Armazenagem, $2001 ; \mathrm{n}^{\circ} 127$ : May 2001.

8. Laarhoven, $P$ van, Berglund, $M$, Peters, $M$. Third-party logistics in Europe - five years later, International Journal of Physical Distribution \& Logistics Management, 2000 ; 30: $425-442$.

9. Lewis, I, Talalayevsky, A. Third-party logistics: leveraging information technology, Journal of Business Logistics, 2000 ; 21: 173-185.

10. Monteiro, LF, Collura, M, Applegate, LM. E-commerce in Latin America, , Harvard Business School publication $\mathrm{n}^{\circ}$ 9-801-388, June 2001.

11. Ng, P. FedEx corp: structural transformation through e-business, Centre for Asian Business Cases, School of Business, The University of Hong Kong, publication $n^{\circ}$ HKU098, Jan 2000.

12. Revista Tecnologistica . Brazilian market for 3PLs (in Portuguese), $n^{\circ} 67$, June 2001a.

13. Revista Tecnologistica. A survey classifies logistics service providers in Brazil (in Portuguese), $\mathrm{n}^{\circ}$ 70, September $2001 b$.

14. Skjoett-Larsen, T (2000). Third party logistics - from an interorganizational point of view, International Journal of Physical Distribution \& Logistics Management, 2000 ; 30: 112-127.

15. Sum, CC, Teo, CB. Strategic posture of logistics service providers in Singapore, International Journal of Physical Distribution and Logistics Management, 1999 ; 29: 588-605. 